\title{
Geophysical monitoring of subsurface contamination in two-phase porous media
}

\author{
Jincai Zhang ${ }^{1 *}$ Hartmut Spetzler ${ }^{1,2}$ \\ ${ }^{1}$ CIRES, University of Colorado, Boulder, CO 80309, USA \\ ${ }^{2}$ Department of Geological Sciences, University of Colorado, Boulder, CO 80309, \\ USA
}

\begin{abstract}
We have explored a new technology based on using low-frequency strain attenuation data to monitor the infiltration of contaminants into two-fluid phase porous materials. The attenuation mechanism is related to the loss of energy due to the hysteresis of resistance to meniscus movement (changes in surface tension and wettability) when a pore containing two fluids is stressed at very low frequencies. This phenomenon was verified in our laboratory experiments and applied to a field study near Maricopa, Arizona. In the field study we conducted controlled experiments with the aim of detecting and monitoring the infiltration of a contaminant - a biosurfactant into groundwater. Three sets of geophysical instruments, each consisting of a 3component seismometer and a tiltmeter, were installed near an irrigation site. The experiment lasted about 3 years with controlled irrigations of initially water only and then water with contaminant into the vadose zone. We used naturally occurring signals of microseisms for our seismic sources and solid Earth tides as sources for the tilt signals.
\end{abstract}

To process the tilt data we extracted the tidal signal from the raw data, and then compared the measured tidal signals with site-specific theoretical data. Changes in tidal signals indicate a strong anomaly associated with the irrigation when a 150 ppm concentration of a biosurfactant was present. No such anomaly was detected when only water was used. Further data processing with an automated procedure shows that the anomalies still persisted. Furthermore, the microseismic results from the seismic data suggest that there may also be a detectable anomaly.

\footnotetext{
* Now at Hess Corporation, email: zhangjincai@yahoo.com
} 


\section{Key words}

Geophysical monitoring; solid tides; tilt; microseismic; groundwater contaminant; field test.

\section{Introduction}

Non-invasive geophysical monitoring techniques are increasingly applied to the petroleum industry to monitor hydraulic fracturing and oil production (such as microseismic method: e.g., Vinegar et al., 1992; Cornet et al., 1997; Dohmen et al., 2013; Dohmen et al., 2014). When tackling environmental problems associated with contaminant remediation, it is essential to monitor the processes in the subsurface (Snieder et al., 2007). Therefore, the geophysical monitoring techniques are also important for environmental protection to monitor groundwater contamination. In-situ geophysical monitoring of subsurface fluid saturation changes and contamination is important for environmental protection and oil industry, for instance (1) leakage at buried waste sites, (2) contaminant remediation in groundwater, and (3) fluid injection for enhanced petroleum recovery. Geophysical monitoring of groundwater contamination has been examined by many methods with geophysical instruments (e.g., Greenhouse and Monier-Williams, 1985; Benson et al., 1997; Buselli and Lu, 2001; McGlashanb et al., 2012). Commonly-used geophysical methods for monitoring groundwater contamination and plume migration include geoelectrical methods (e.g., Mazac et al., 1987; de Lima et al., 1995; Benson et al., 1997; Sauck, 2000; Nwankwo and Emujakporue, 2012; Bellmunt et al., 2016) and ground penetrating radar methods (e.g., Benson, 1995; Daniels et al., 1995). However, for trace amounts of groundwater contaminations in terms of concentration, the current methods may not have enough resolutions to detect them. Therefore, we tested a new technique at a controlled irrigation site near Maricopa in Arizona with the aim of detecting the infiltration of a small amount of contaminant - a biosurfactant - into the vadose zone. This represents a near ideal arrangement to experimentally check if the contaminant in the groundwater can be detected by geophysical instruments.

The field studies described here find their origin in laboratory studies. We

designed and built an attenuation spectrometer for attenuation measurements from 
periods of 0.01 seconds to 10,000 seconds (e.g., Waite et al., 1997; Brunner and Spetzler, 2001; Brunner et al., 2003). Prior to the in-situ measurements, we conducted laboratory experiments where the influence of contaminants on fluid flow across solid surface was studied. We found that contaminants alter the surface tension and affect the meniscus properties and thus the flow of fluids in a partially saturated medium. In the laboratory experiments small additions of some chemicals to water can drastically change the surface energies and thus the wettability of solid surfaces. Surface energy changes in a partially saturated porous rock lead to large changes in complex elastic moduli. In the laboratory experiments, a single core plug of Berea sandstone was used for these attenuation measurements. This sample was cut into a right circular cylinder having a length of $0.102 \mathrm{~m}$ and a diameter of $0.0254 \mathrm{~m}$ (Brunner and Spetzler, 2002). The experiments show that much higher attenuation is apparent in the contaminated sample than in the clean sample (Fig. 1). Figure 1 demonstrates the effect of a graincoating contaminant (propanol) on the attenuation of seismic energy while the sandstone was stressed at a low frequency $(0.1 \mathrm{~Hz})$. In the "clean" case, the sandstone was fully saturated with water when the attenuation measurements began, and was allowed to air-dry while measurements continued. In the "dirty" case, the dry sandstone was flushed with a contaminant, air-dried, then fully saturated with water such that the grain surfaces were coated with the contaminant, but the primary liquid was water. Attenuation was again measured while the sample was allowed to air-dry while measurements continued. As the low frequency attenuation mechanism theory predicts, there is greater attenuation (energy loss) in the contaminated "dirty" sandstone than the clean one. We attribute this to the loss of energy in the partially fluid-saturated sandstone sample due to the change in the wettability of the porous system. In other words, when the grains are contaminant-coated, there is a greater resistance of fluid movement than when the grains are "water-wet". The small negative attenuation for the clean sample is due to a persistent phase shift in the attenuation spectrometer. Shown in Fig. 1 are the raw data and the shift gives an indication of the uncertainty of the absolute attenuation, verified with aluminum samples of similar moduli. The field investigation was based on these laboratory results and we anticipated to see a similar change in contaminated subsurface. In the field experiment we changed the wettability of the subsurface and analyzed seismic 
and tilt data at varying distance from the irrigation site for contaminant-caused changes in the moduli. In this paper, we present the results of the field study in which we explored the detection of the infiltration of contaminants through the vadose zone into the groundwater.

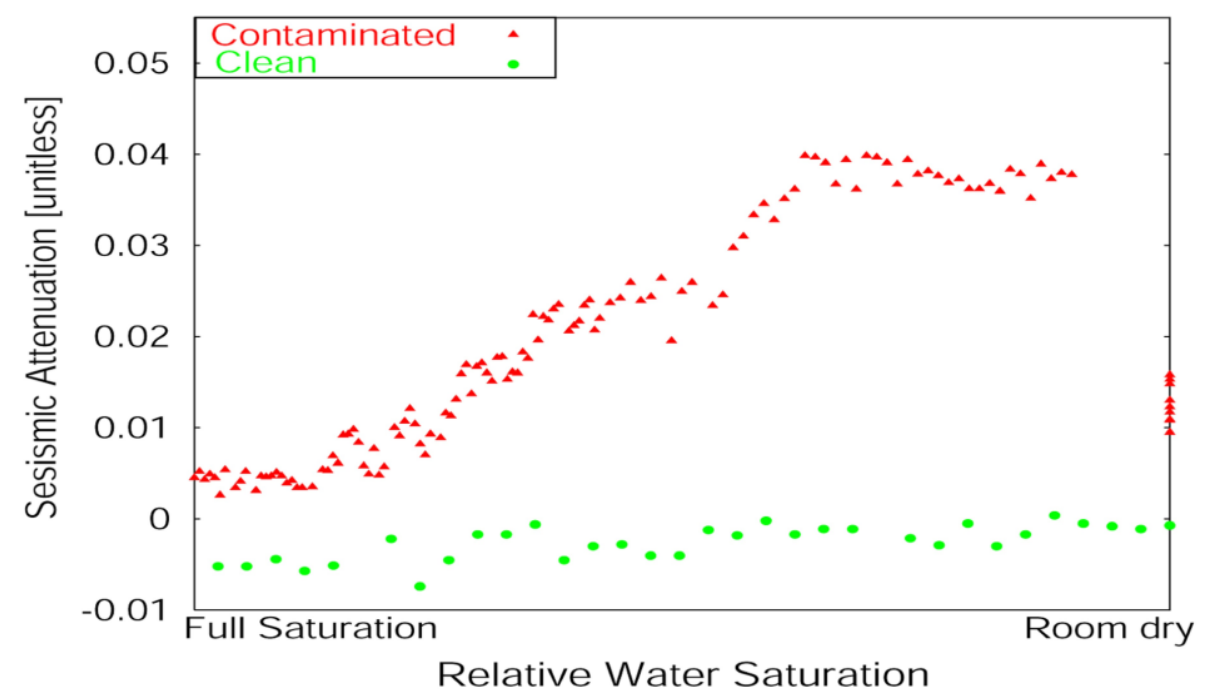

Fig. 1. Effects of contamination and saturation on attenuation in sandstone: attenuation is shown as a function of water desaturation in a clean and a propanol-contaminated Berea sandstone sample (Brunner and Spetzler, 2002).

\section{Field site description}

We have conducted a three year field study at the Maricopa Agricultural Center (MAC) site of the University of Arizona. At the center a controlled irrigation site was built for the study of water migration from the surface to the groundwater. It has been a research and teaching site with extensive facilities for irrigation, located about $64 \mathrm{~km}$ south-east of Phoenix near the town of Maricopa. The $50 \mathrm{~m}$ by $50 \mathrm{~m}$ area was covered with a heavy black tarp and equipped with irrigation pipes spaced about $1 \mathrm{~m}$ apart. The field was subdivided into 6 zones that could be irrigated separately. Sampling holes allowed for water sampling from near the surface to a depth of $10 \mathrm{~m}$. The groundwater level was generally near $15 \mathrm{~m}$ or a little shallower. During irrigation, which lasted several weeks, water from 2 tanks, holding about 26,000 liters each, was applied at the rate of about 3 liters/second alternating between the 6 zones. A total of 
approximate 45,000 liters of water was applied every day during a 12 hour period. The tanks were equipped with circulating pumps for mixing of additives. The soil at the site was characterized as Sandy Loam to Sandy Clay Loam soil (Post et al., 1988).

Commencing in late August 2002 we drilled 3 holes to a depth of $10 \mathrm{~m}$ (see Fig. 2) near the irrigation area of the site and cased them with plastic pipes and quick set concrete (Spetzler, 2005; Spetzler et al., 2005). Within the constraints of the field site, the holes were located to maximize the sensitivity for detecting changes within the irrigation site. Three sets of instruments were installed along an East-West line perpendicular to the irrigation site (see Fig. 3; Zhang et al., 2002). Each set of instruments consisted of one tiltmeter and one three-component seismometer (Fig. 4). The Tiltmeters (Series 5000), on loan from Pinnacle Technologies in San Francisco, were installed in these holes and surrounded with dry sand to assure good contact with the borehole walls. Three 3-component seismometers (LT-4) were installed on concrete pads at a depth of $1 \mathrm{~m}$. They were surrounded by Styrofoam and protected from water via an inverted plastic bucket. The necessary instrumentation including the data acquisition (RefTek) was located in a nearby plastic box that was buried and covered with a tarp and approximately $10 \mathrm{~cm}$ of soil. The seismometers were on loan from Professor Craig Jones of the University of Colorado and the data acquisition systems from Passcal at New Mexico Tech. in Socorro, NM. Standard AC power was available at the site. The power for all instruments was provided from batteries, which had trickle chargers connected to them. Tilt values were samples at 50 second intervals and seismic data were generated at 50 samples/second.

After the boreholes stabilized and instruments settled down, we irrigated the site twice for the in-situ geophysical monitoring tests. The first time we used water only, starting in late October of 2003 for a period of about 5 weeks. The second time we added a biosurfactant (JBR425 Rhamnolipid Biosurfactant from Jeneil Biosurfactant Co.) to achieve a concentration of $150 \mathrm{ppm}$ and irrigated for a 6 week period starting in middle October 2004. This biodegradable additive served to mimic a class of contaminants that change the surface tension of the irrigation fluid. At concentrations of $>50 \mathrm{ppm}$ the surface tension of water was reduced by more than a factor of 2 . We recorded the tiltmeter and seismic data nearly continuously from 
August 2002 until April 2005. We used the natural solid Earth tides and microseisms as strain sources. The following section shows the processing and analysis of the data.

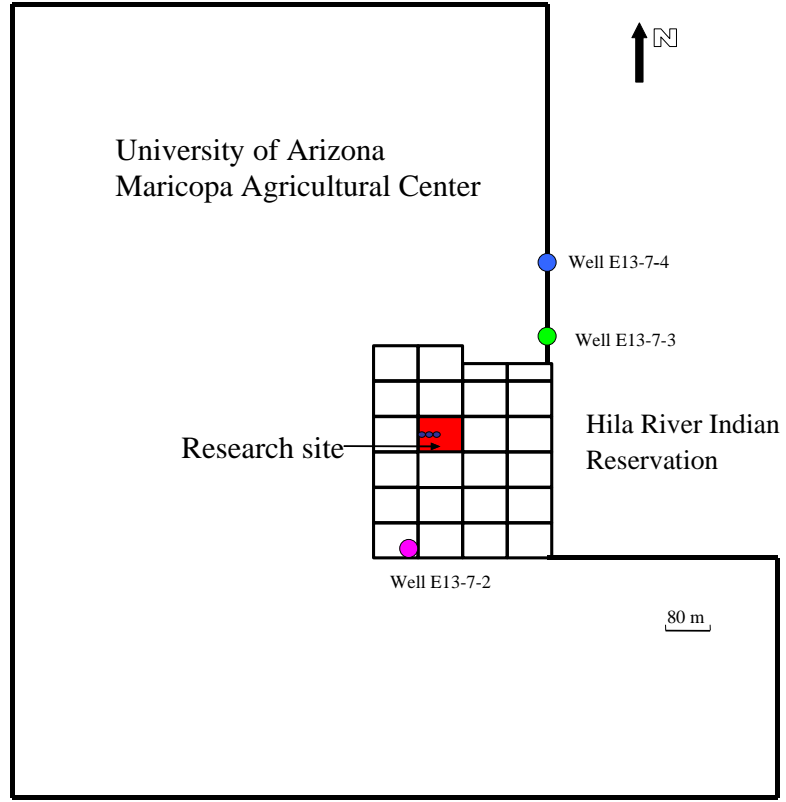

Fig. 2. Field site with 3 existing irrigation wells and 3 newly drilled boreholes in the highlighted area for geophysical monitoring at the Maricopa Agricultural Center.



Fig. 3. This schematic diagram showing 3 tiltmeters were installed at a depth of about $10 \mathrm{~m}$ in each cased hole and 3 seismometers were buried at about $1 \mathrm{~m}$ deep. 


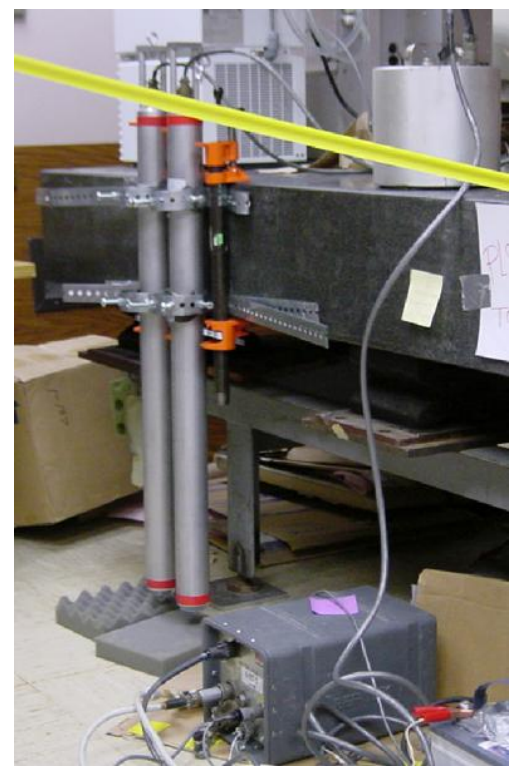

Fig. 4. The picture showing tiltmeters (left), RefTek recording system (bottom) and seismometer (top) tested in the lab prior to installation.

\section{Data processing and analysis}

The purpose of the data analysis was to develop a technique for processing the geophysical data to distinguish the tiny changes due to the contaminations in the vedose zone and groundwater. It was not a conventional way of data processing for our non-traditional use of the data, since the variations in instrument responses caused by the trace amount of contaminants were small. The data processing for the two kinds of (seismometers and tiltmeters) data were different and are shown in the following.

\subsection{Tilt Data}

The acquired raw data from the tiltmeters consisted of two extreme different categories: one were the large events caused by the deformations of the formation, such as regional water pumping for livestock and irrigation, oil productions, and also earthquakes, etc. The other category consisted of the local tiny events caused by the deformation in the vadose zone, such as the Earth solid tides, contaminations in the vadose zone, rainfall, and temperature changes, etc. Figure 5 shows the typical data as they were recorded by the tiltmeters in the field. Note that there was correlation as well as anti-correlation between the EW and NS tilts which depended on the direction 
to the noise source. We obtained some interesting results in the Alaska earthquake of Nov. 3, 2002. The East-West direction had much larger tilt than the North-South direction during the M7.9 earthquake. The formation had an offset tilt toward the west, meaning that the earthquake induced a permanent discontinuous deformation in the formation in Arizona. At the scale shown in Fig. 5 the tidal tilts are not obviously observable because agricultural and other background noise dominates. The challenge is the extraction of the tidal signal so it can be compared with the theoretical tidal data.

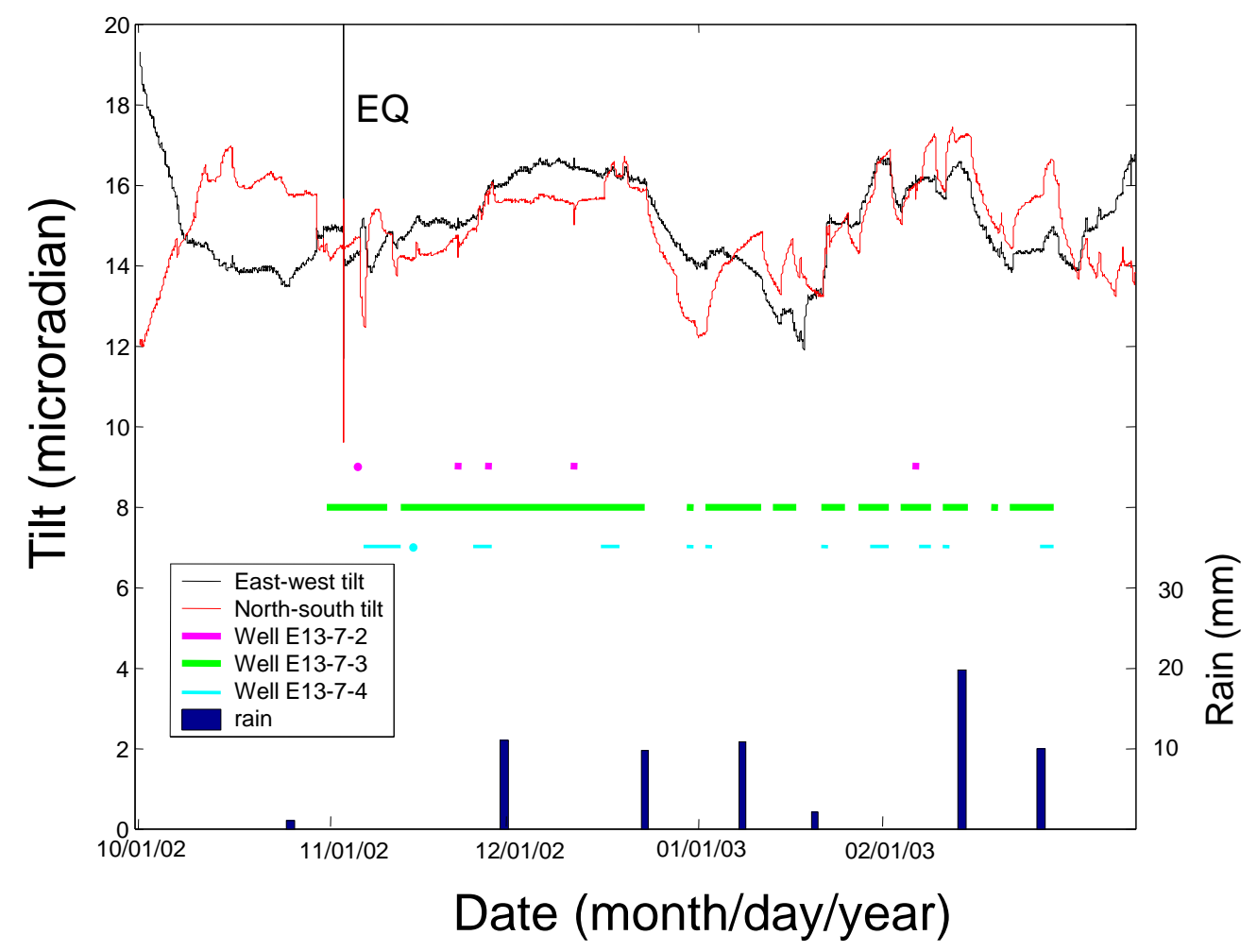

Fig. 5. The tilts recorded (East-West, North-South tilts, rainfall and the activity of nearby pumps for agricultural irrigation) at Well 1 for a period of about 5 months.

In order to detect the contaminations in vadose zone and adjacent groundwater, we examined the local tiny events, i.e., changes of the local Earth tides. Our idea is based on that the soil and water properties in the contaminated and uncontaminated formations have different soil and water properties and these differences should cause variations in the solid tide behaviors. To examine the tiny local signals (the local solid tides) it is necessary to first get rid of the large events. The key issue during the process of removing the large events was to make sure that the tidal signals were not removed. Therefore, a method and corresponding codes for automatically cutting off 
the data induced by the large events were developed. The followings are the procedures of this method (Zhang and Spetzler, 2003):

(1) Remove the long term trend by using the linear fit of certain long period data, e.g., linear deformation caused by the initial settling of the boreholes after instrument installation in Fig. 5.

(2) Remove very large events, such as earthquakes etc. (Fig. 5) by using the corresponding theoretical solid tide derivatives to replace the derivatives in the very large events. These replacements would not affect the real tilt data, because there are only a few of these very large events in the in-situ data.

(3) Remove the large events (e.g., agricultural irrigations) by using linear fits to the data for each zero-crossing of the theoretical tide data and retaining the residuals. The zero-crossing linear fits assure that observed tide data are not discontinuous.

(4) Process the selected data in the time domain to keep the tilt data in the initial and final points are zeros for shifting the data in order to compare the tilt data to the theoretical tilts of the Earth tides.

(5) Use the low-pass Butterworth filter (5 to 40 hours) to get rid of noise and retain the strong tidal signals with periods of 12 and 24 hours.

After completing the above processing, the remaining signals are the local tide data. We compared these observed data with the corresponding theoretically generated tide signals at the same scale (Fig. 6). Then, we calculated the correlation coefficients between the theoretical tide data and processed tilt data for different wells. Finally, we examined these data in a time domain for a long time period to find the variations of the tide data for different stations over time. These variations should be connected with the property changes of the vadose zone caused by contamination. 


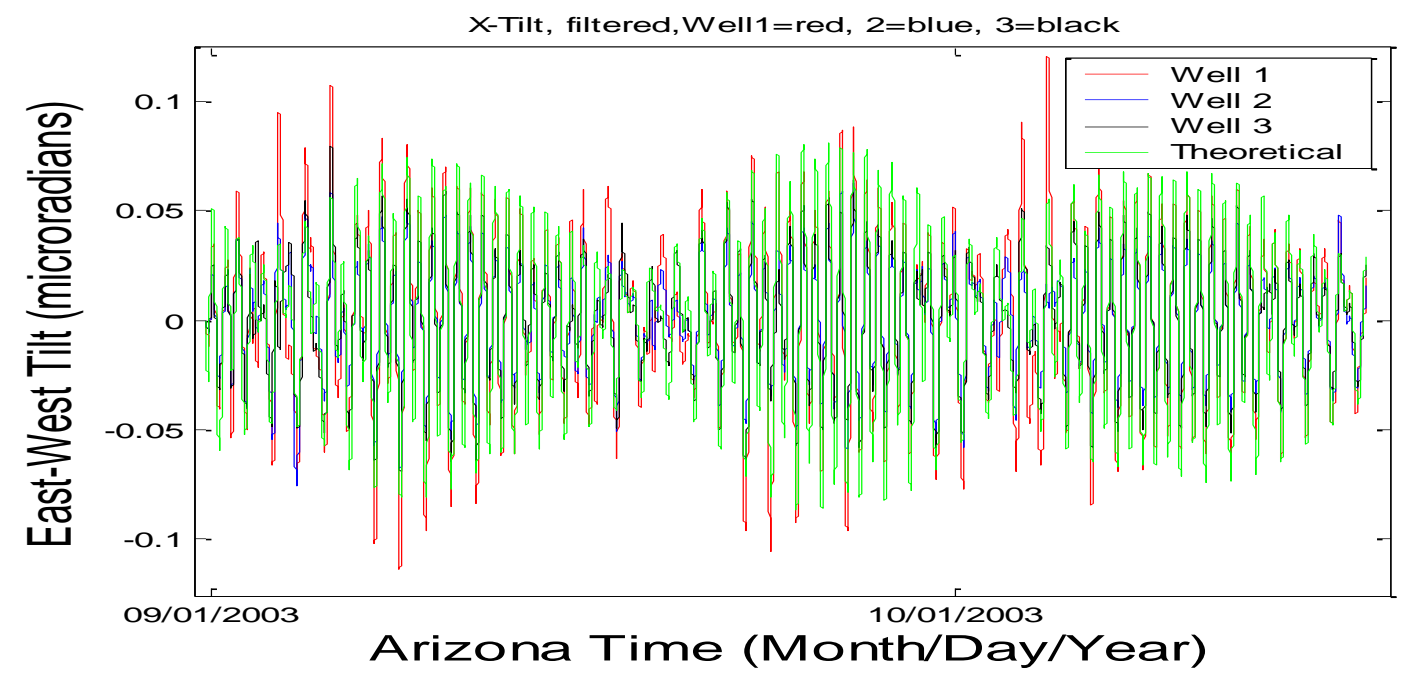

(a)



(b)

Fig. 6. Processed tilt data in three wells compared with theoretical tilt. (a) from Sept. 1 to Oct. 17, 2003; (b) enlarged plot from Oct. 5 - 13, 2003.

Figure 6 presents the processed tilt data in three wells after eliminating large events and removing other extraneous noise by using a band-pass filter (5 to 40 hours) on the raw tilt data. The processed tilt data were compared with the site specific theoretical tilt of the Earth tides provided by Dr. Judah Levine (J. Levine, personal communication with H.S., and Levine and Harrison, 1976). These processed data can then be used for analyzing the contamination (biosurfactant irrigation) impact in the 
groundwater. Figure 7 shows the correlation coefficients between the theoretical and the processed East-West tilts (based on the procedures described above) for the three stations, including the two irrigation periods. From Fig. 7: when the processed tilts in the observed tilt data are correlated with site specific theoretical tilt signals, we see no anomalies for the water irrigation, but large anomalies on two stations for the surfactant irrigation. Note that the large anomaly, especially for well 2, appears to be associated with the biosurfactant irrigation. The onset of the anomaly was about two weeks into the irrigation and the end about the same period after the irrigation ended. This two-week period was the time for the ground to become saturated and the surface water to reach the ground water. We do not understand at this time why the anomaly for well 1 was so much smaller than that for well 2. This motivates us to pursue further data processing and modeling to analyze if the anomalies were caused by the surfactant irrigation.
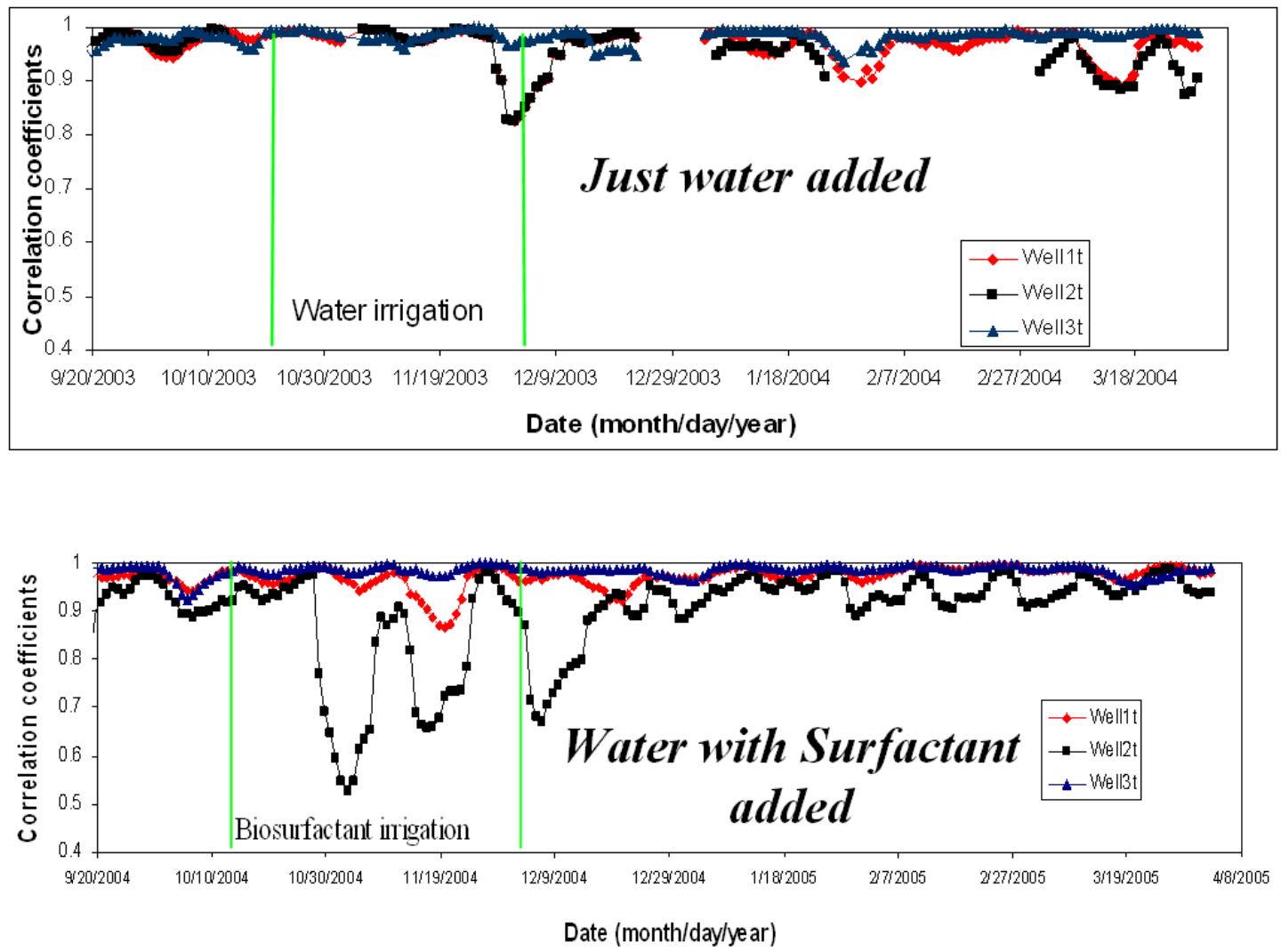

Fig. 7. The East-West correlation coefficient between theoretical tilt and measured tilt are plotted for periods of water irrigation and water with surfactant irrigation. The 
array of instruments was arranged in an E-W direction and the E-W tilts were larger because of the ecliptic plane.

In the further data processing, we firstly identified background noise signals and then removed them. Figure 8 shows a rather clean case that illustrates how exponential signals resulting from pumping are removed. We wrote a series of programs to automate the fitting routines, systematically go through the signal, select sections, then fit these sections exponentially and remove the background. The description of this logic of the programs can be found in Spetzler et al., (2009).

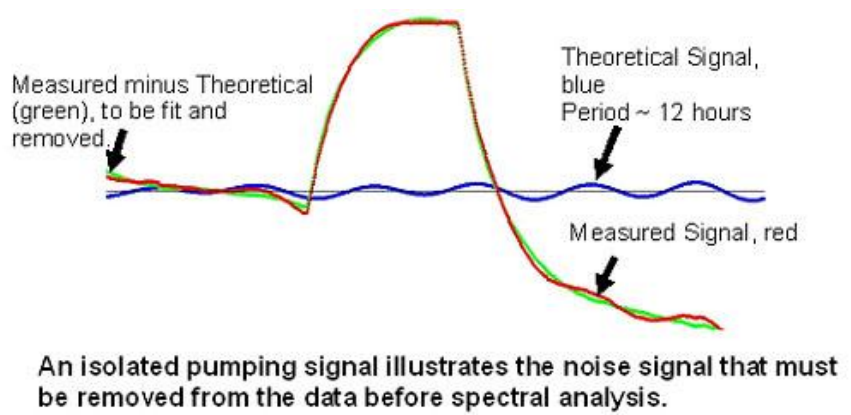

Fig. 8. The pumping signals show clear exponential trends and are rather easily removed (modified from Spetzler et al., 2009).

The first frame in Fig. 9 shows a typical signal of raw data retrieved from a tiltmeter. The raw data were de-trended first, i.e. long term drift was removed using the software provided by Pinnacle. Then, much of the background noise was extracted in a series of programs we wrote as shown in the following:

A.) Prepare data for filtering and noise removal that is near tidal periods. This first set of programs removes noise that has periods far from tidal periods, but could cause large ringing when filtered.

1.) Remove spikes with a median filter.

2.) Remove very steep slopes by replacing the steep sections with the corresponding theoretical slopes.

3.) Smooth transitions with a polynomial function

4.) Remove constant values, as might result from a stuck bubble in the tiltmeter, by their corresponding theoretical values. 
B.) The next program removes those events, which have periods near the tidal periods. As shown in Fig. 10, the program selects a section of the signal from bin bs (bin-start) to bf (bin-finish). A variable window, ws to wf slides from bs toward bf until the end of the widow coincides with bf. It then performs the following tasks:

1.) Calculate an amplitude (last value minus first value) for each window from ws to wf in steps of $\mathrm{n}$. It does this for each bin from bs to bf-wf.

2.) Locate the maxima of the amplitudes and sort them from largest to smallest; with a cutoff at the small end that is determined by some multiple of the maximum theoretical amplitude; (amp_cut_off).

3.) Starting with the largest amplitude and proceeding to the smallest, the program searches (with step sizes of one) for a best fit in the vicinity of the maxima. It can use polynomials of 1 st, 2nd and 3rd order as well as exponentials with different numbers of variables.

4.) If the "Best Fit in the Vicinity" of a particular amplitude is better than the predetermined "acceptable value" the fit is accepted. The "Best Fit in the Vicinity" means that the program searches for the position within the signal (bin number) as well as the best window width.

5.) Then subtract the fit from the signal and generate a new signal. The process starts over.

6.) The program keeps going until it cannot find an acceptable fit among all amplitudes, or until there are no more amplitudes larger than the “amp_cut_off”.

After completing the processing mentioned above, the resultant signal can then be compared with the theoretical signal to determine anomalies. Both signals are band-pass filtered between 4 and 52 hours to include the 12 and 24 hour tides. A 14 day Hanning window is moved in 2 day steps cross both signals and their amplitude ratios are calculated. 
Logic of finding the best fit

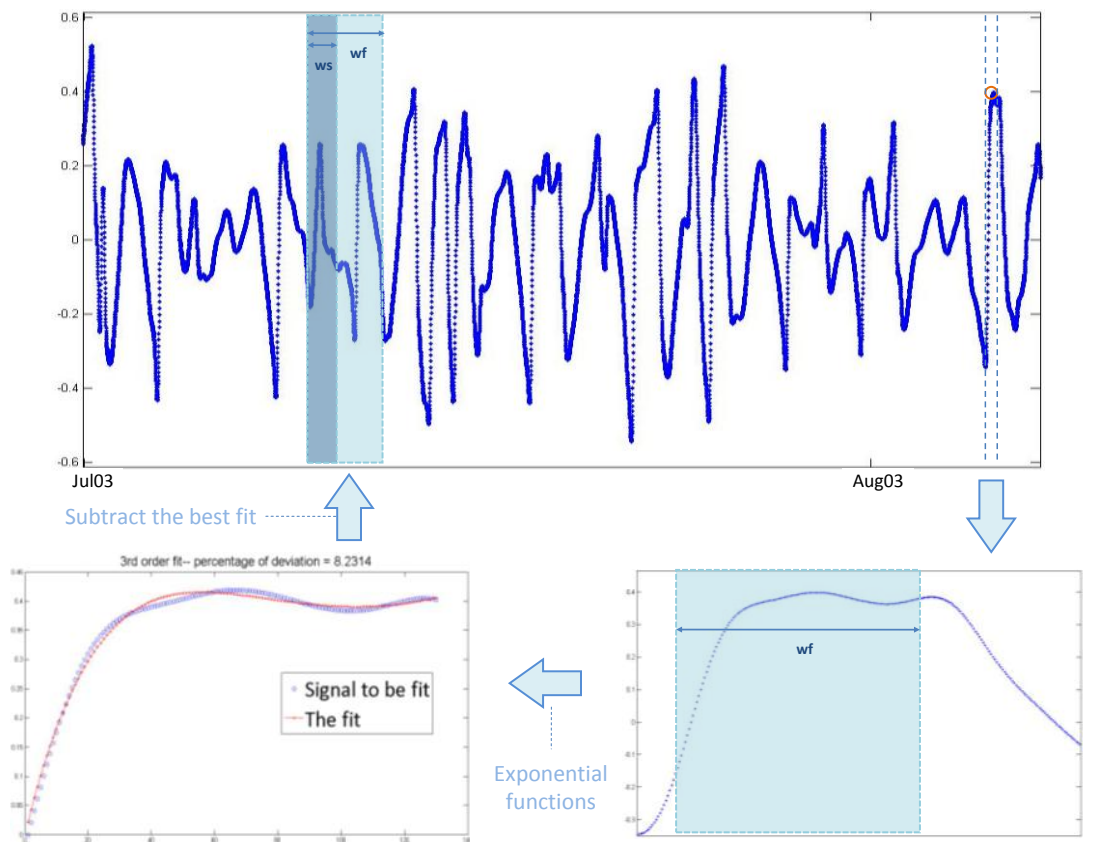

The program will stop if it cannot find a large amplitude or a good fit.

Fig. 9. The top trace shows noisy raw data during the summer of 2003 with the shaded areas ws, the starting window and wf, the final window. The indicated section toward the right of that trace was selected to illustrate fitting. It is shown enlarged at bottom right. The bottom left shows the fit in red and the signal that was fit in blue. The difference between the two is the extracted "tidal part" of the signal. 


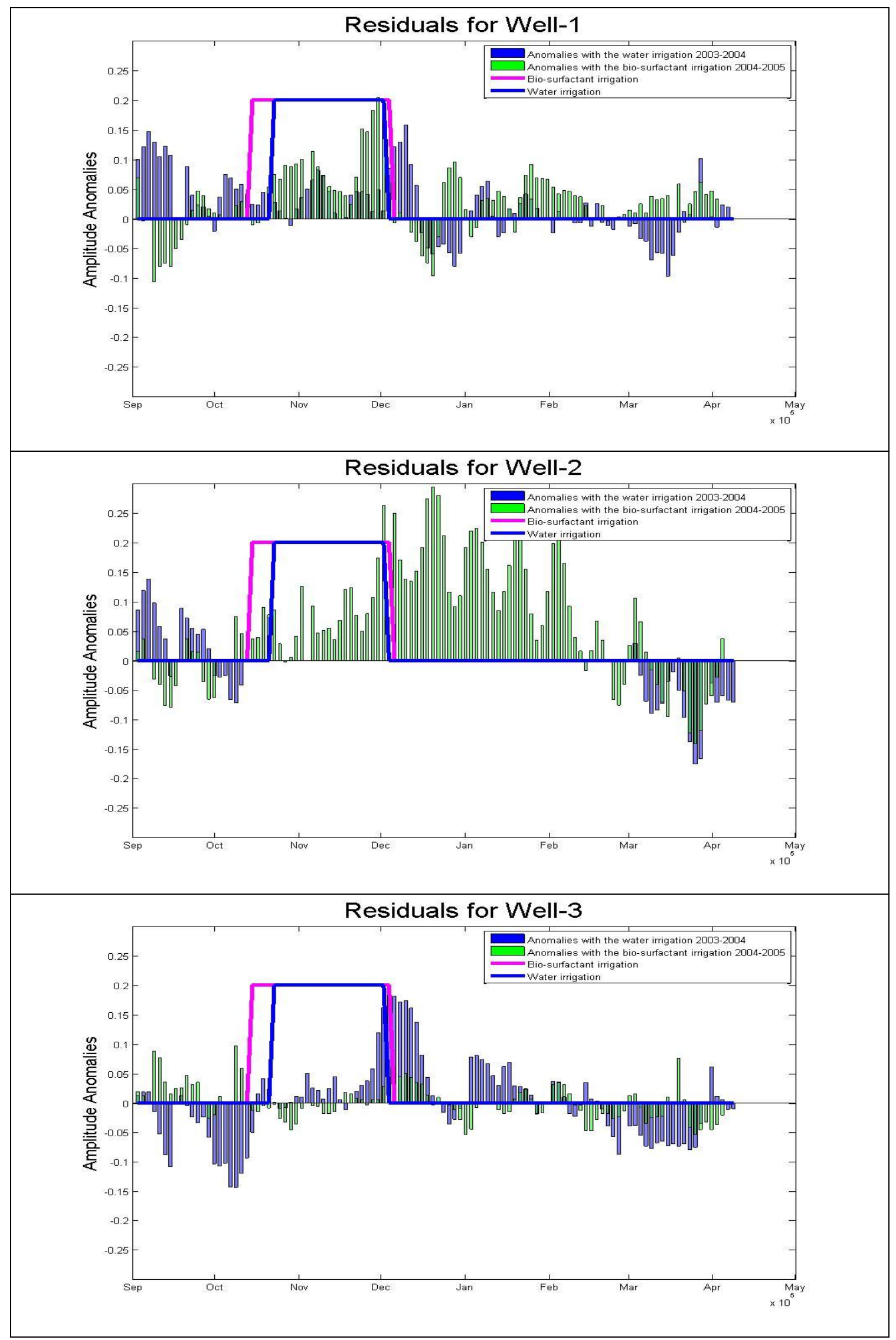


Figure 10. The anomalies in processed superimposed data for approximately 7 months including the periods of the two irrigations in 3 wells.

Figure 10 shows the anomalies from September 2003 through April 2005 including the two irrigation periods. The data were superimposed such that the anomalies could be better compared. The tiltmeter in well 2 failed just before the water irrigation in 2003 and was not replaced with a new instrument until the spring of 2004. The generally noisier data for the hot summer months were not included in this time period. It appears in Fig. 10 that the anomalies, originally detected in Fig. 7, still persist when an automated procedure was used.

From Figs. 7 and 10 we can see that the processed tilt data for well 1 and well 2 show anomalies in the surfactant irrigation period. However, the processed tilt data in well 3 do not have such anomalies, and this might be caused by incorrect setting of the instrument's resolution. Well 3 shows low correlation values from Fig. 7. It is located very close to a road that was used by heavy farming equipment.

\section{2. $\quad$ Seismic Data}

Seasonal changes in the amplitude ratios of signals from microseisms have been found in California (Tanimoto et al., 2006). These seasonal changes were likely caused by rather shallow changes in the water table as well as in partially saturated level in the vadose zone. For our seismic data, not only did we examine the large events, such as earthquakes, but also the microseisms caused noise emanating from the ocean. Since microseism signals were very weak, first step for data processing was to select relatively quiet time periods (such as around midnight) for data collection. Then, we used ten-point averaging of the data to reduce random noise. Finally, we used a Butterworth band-pass filter from 1 to 10 seconds to remove high frequency noise (the power of microseisms peaks at 6 seconds).. After this processing, we calculated the correlation coefficients for the three wells in the time domain to 
compare the differences among the three stations over time. The purpose was to find tiny differences in the signals of the microseisms at varying distances from the irrigation site. The idea was based on the assumption that the locally disturbed vadose zone and adjacent groundwater had different effects on the seismic propagations (Zhang et al., 2004).

Figure 11 shows a typical power spectrum of microseisms from one of our seismometers in May 2004. The microseismic signals reached the maximum at $\sim 0.15$ Hz. We chose microseisms because they are ubiquitous akin to the tides. However their intensity depends on the wave activities in the oceans, which is somewhat variable. We analyzied the power spectrum of microseisms in all three components (i.e., one vertical and two horizontal components); however, we used the vertical components because it was less noisy. Figure 12 shows the power spectral ratios for the vertical components between Wells 1 and 2. Note the onset of what appears is an anomaly several weeks into the irrigation with a surfactant. This anomaly disappears again several weeks after the irrigation ceases. For comparison the tilt data in Fig. 7, the microseismic results seem encouraging for detecting the anomalies. However, occasional failures of seismometers as well as data acquisition systems contributed to less than continuous coverage. These data were noisier than the tilt data, but did also show possible anomalies for the irrigation of the biosurfactant. 


\section{Well2}
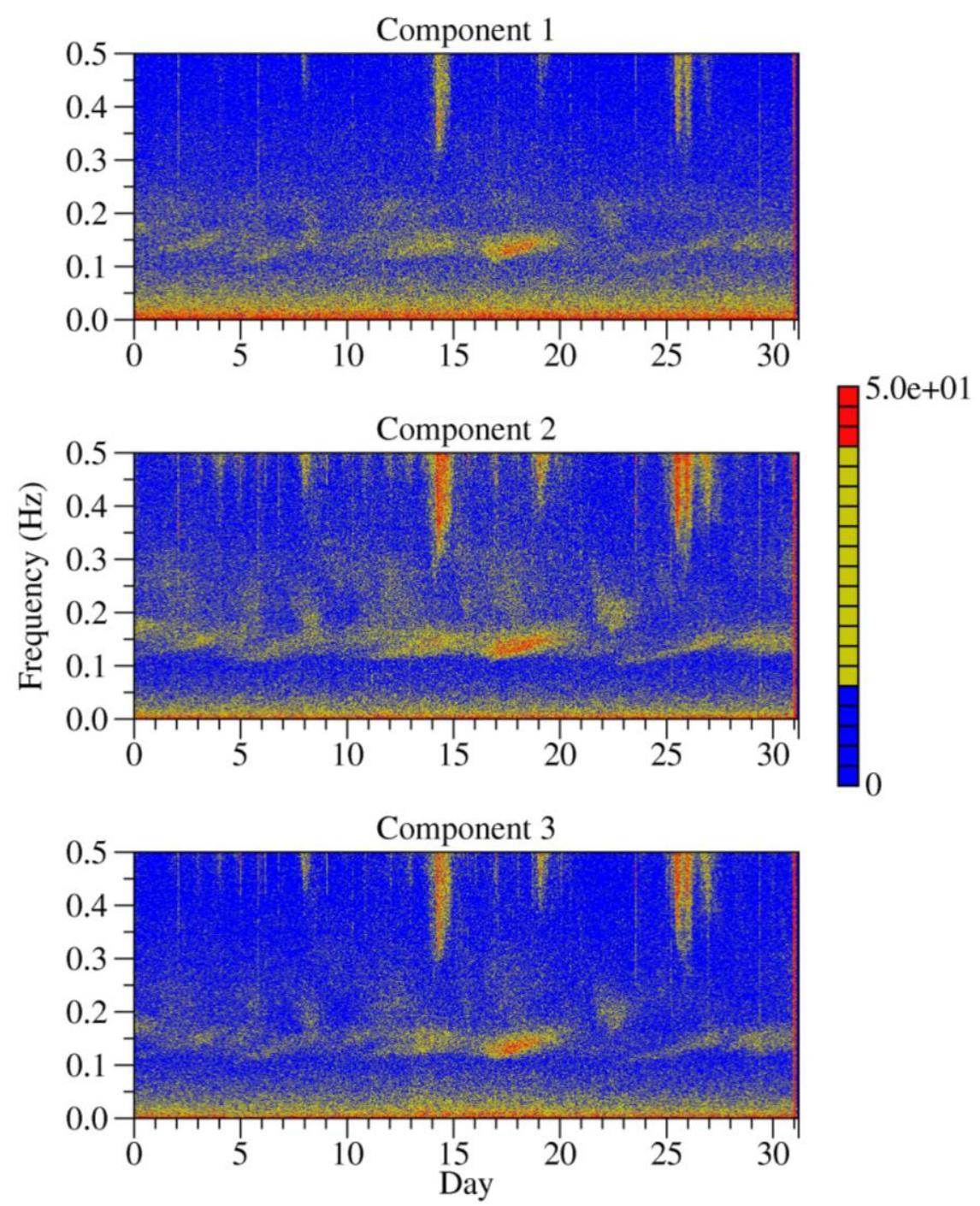

Figure 11. Power spectrum of microseisms in seismic signal for a one month period in 3-component seismometer buried $1 \mathrm{~m}$ below the surface close to Well 2 . 
$.1-.2 \mathrm{~Hz}$ Power Spectral Ratio



Figure 12. Power spectral ratios of the vertical components between Wells 1 and 2.

\section{Conclusions}

This paper describes the use of natural strain signals, solid Earth tides and microseisms to extract information about minute local changes in the subsurface. The field studies described here find their origin in laboratory studies. We designed and built an attenuation spectrometer for attenuation measurements from periods of 0.01 to 10,000 seconds. In our laboratory experiments small additions of some chemicals to water drastically changed the surface energies. The surface energy changes in a partially saturated porous rock lead to large changes in complex elastic moduli. Therefore, geophysical methods should be able to detect the changes of rock/soil properties in the subsurface, consequently find the changes caused by the contaminated chemicals in the groundwater. Based on the laboratory results a threeyear field experiment designed to test the feasibility of detecting infiltration of a biosurfactant into groundwater was conducted. We employed tilt meters and seismometers to record spatial and temporal changes in tilt and natural seismic data to extract solid Earth tides and microseismic signals caused by physical changes near an irrigated site. A series of programs were written to process the recorded data and extract tidal signals and microseismic signals from the raw data. Changes in tidal signals indicate a strong anomaly associated with the irrigation when a $150 \mathrm{ppm}$ concentration of a biosurfactant was present. No such anomaly was detected when 
only water was used. Further data processing with an automated procedure shows that the anomalies still persisted. Furthermore, the microseismic results from the seismic data suggest that there may also be a detectable anomaly, but it is less certain. For microseismic data, analyzing seismic coda waves may yield better results for examining soil-fluid (water or waste fluid) responses.

The site at Maricopa was very noisy with constant agricultural activities including agricultural irrigation, tilling, construction, harvesting etc. It took over one year before the major drift related to the settling of the boreholes subsided. And seasonal changes have been found in both microseism and tilt data. In addition, the concentration of the biosurfactant in the groundwater in our test was very small, only very high resolution instruments could detect it. Although those unfavorable environments, it seems promising to identify soil and water contamination by using microseism and tilt. The results of this study, while not overwhelming, suggest that at a more favorable location the application of long term tilt measurements (combining with electrical and other methods) to monitor contaminations in the vadose zone may be appropriate.

\section{Acknowledgements}

Prof. Judah Levine calculated the site-specific tidal tilt data for us, which were fundamental to this work; we are greatly indebted to him. We would like to thank Pinnacle Technologies and PASSCAL for providing the instruments. Thanks to the Maricopa Agricultural Center of the University of Arizona for providing the experiment site. The Funding for this project was provided by DOE, under the grants DE-FG3-94ER14419, DE-FG3-94ER14518, and DE-FG02-06ER15779. The tiltmeters were provided by Pinnacle Technologies and the Seismic data acquisition systems and sensors were provided by PASSCAL at New Mexico Tech. and the Department of Geological Science at the University of Colorado, Boulder. Access to the Maricopa Agricultural Center was provided through the courtesy of the University of Arizona. We would also like to thank the following people, without whose help we could not have conducted this research: Dr. Mike Yao and Prof. P.J. Wierenega from

the University of Arizona in Tucson AZ, Mr. Tony Gomez, Dave Langston, Dan 
Warren, Ed Martin, Vince Tacker and Ms. Carol Jenkins from the Maricopa Agricultural Center, Mr. Gary Sloan of the Maricopa Stanfield Irrigation and Drainage District, Prof. Toshiro Tanimoto from the University of California at Santa Barbara, Prof. Anne Sheehan and Dr. Wendy Wempe from the University of Colorado, Mr. David Spetzler of Arizona State University in Tempe, Prof. Roel Snieder and Dr. Xia Qin from the Center for Wave Phenomena, Colorado School of Mines, Golden.

We thank the editors and reviewers for their constructive suggestions.

\section{References}

Bellmunt, F., Marcuello, A., Ledo, J., Queralt, P., 2016. Capability of cross-hole electrical configurations for monitoring rapid plume migration experiments. J. Applied Geophys. 124, 73-82.

Benson, A.K., Payne, K.L., Stubben, M.A., 1997. Mapping groundwater contamination using DC resistivity and VLF geophysical methods - a case study. Geophysics 62 (1), 80-86.

Benson, A.K., 1995. Applications of ground penetrating radar in assessing some geological hazards: examples of groundwater contamination, faults, cavities. J. of Applied Geophysics 33, 177-193.

Brunner, W.M., Spetzler, H.A., 2002. Contaminant-induced mechanical damping in partially saturated Berea sandstone. Geophys. Res. Lett., 29(16), 10.1029/2002GLOI5455.

Brunner W.M., Getting, I.C., Spetzler, H.A., 2003. A device for the independent verification of subresonant mechanical damping measurements. Review of Scientific Instruments, 74(4), 2604-2610.

Brunner, W.M., Spetzler, H.A., 2001. Observations of time-dependent meniscus behavior with implications for seismic attenuation in three-phase systems. GRL, Vol 28, No. 9, 1867-1870.

Buselli, G., Lu, K., 2001. Groundwater contamination monitoring with multichannel electrical and electromagnetic methods. J. Appl. Geophys. 48, 11-23.

Cornet, F.H., Helm, J., Poitrenaud, H., Etchecopar, A., 1997. Seismic and aseismic slips induced by large-scale fluid injections. Pure Appl. Geophys. 150, 563-583. 
de Lima, A.L., Sato, H.K., Porsani, M.J., 1995. Imaging industrial contaminant plumes with resistivity techniques. J. of Applied Geophysics 34, 93-108.

Daniels, J.J., Roberts, R., Vendl, M., 1995. Ground penetrating radar for the detection of liquid contaminants. J. of Applied Geophysics 33, 195-207.

Dohmen, T., Zhang, J., Li, C., Blangy, J.P., Simon, K. M., Valleau, D. N., Ewles, J. D., Morton, S., Checkles, S., 2013. A new surveillance method for delineation of depletion using microseismic and its application to development of unconventional reservoirs. Paper SPE166274 presented at the SPE annual tech. conf. in New Orleans, Louisiana.

Dohmen, T., Blangy, J.P., Zhang, J., 2014. Microseismic depletion delineation. Interpretation, 2(3), SG1-SG13.

Greenhouse, J. P., Monier-Williams, M., 1985. Geophysical Monitoring of Ground Water Contamination Around Waste Disposal Sites. Groundwater Monitoring \& Remediation, 5: 63-69.

Levine, J., Harrison, J.C., 1976. Earth tide strain measurements in the Poorman Mine near Boulder, Colorado. JGR, Vol 81, No. 14, p 2543 to 2556.

Mazac, O., Kelly, W.E., 1987. Surface geoelectrics for groundwater pollution and protection studies. Journal of Hydrology, 93, 277-294.

McGlashanb, M.A., Tsofliasa, G.P., Schilliga, P.C., Devlina, J.F., Robertsa, J.A., 2012. Field GPR monitoring of biostimulation in saturated porous media. J. Appl. Geophys. 78, 102-112.

Nwankwo, C.N., Emujakporue, G.O., 2012. Geophysical method of investigating groundwater and sub-soil contamination - a case study. American J. of Environmental Engineering. 2(3): 49-53.

Post, D.F., Mack, C., Camp, P.D., Suliman, A.S., 1988. Mapping and characterization of the soils on the University of Arizona Maricopa Agricultural Center. Proc. Hydrol. Water Resour. Southwest, Arizona-Nevada Acad. Sci. 18:49-60.

Sauck, W.A., 2000. A model for the resistivity structure of LNAPL plumes and their environs in sandy sediments. J. of Applied Geophysics, 44, 151-165.

Snieder, R., Hubbard, Susan; Haney, Matthew; Bawden, Gerald; Hatchell, Paul; Revil, André, 2007. Advanced Noninvasive Geophysical Monitoring Techniques. Annual Review of Earth and Planetary Sciences, vol. 35(1), 653-683. 2007. 
Spetzler, H.A., Snieder, R., Zhang, J., 2005. Monitoring Contamination of the subsurface with Quasi-Static Deformation Eos Trans. 86(52), AGU Fall Meet. Suppl., Abstract NG33B-0181.

Spetzler, H.A., Snieder, R., Qin, X., 2009. Monitoring the Subsurface with Multiple Scattered Waves and Quasi-static Deformation Principal investigators: Final report for DE-FG02-06ER15779 (April, 2009).

Spetzler, H.A., 2005. Seismic Absorption and Modulus Measurements in Porous Rocks in Lab and Field: Physical, Chemical, and Biological Effects of Fluids (Detecting a Biosurfactant Additive in a Field Irrigation Experiment). Scientific Final Report for DOE-FG02-048R15589.

Tanimoto, T., Ishimarud, S., Alvizuri, C., 2006. Seasonality in particle motion of microseisms. Geophys. J. Int. 166 (1): 253-266.

Vinegar, H.J., Wills, P.B., DeMartini, D.C., Shlyapobersky, J., Deeg, W.F.J., Adair, R.G., Woerpel, J.C., Fix, J.E., Sorrells, G.G., 1992. Active and passive seismic imaging of a hydraulic fracture in diatomite. Paper SPE 22756, JPT.

Waite, W., Moerig, R., Spetzler, H. A., 1997. Seismic attenuation in a partially saturated, artificial crack due to restricted contact line motion, Geophys. Res. Lett., 24, 3309-3312.

Zhang, J., Tanimoto, T., Spetzler, H.A., 2004. Preliminary Application of Microseisms into Groundwater Contamination Monitoring, Eos Trans. AGU Fall Meet. Suppl., Abstract S12B-04, 85(47).

Zhang, J., Spetzler, H.A., 2003. Seismic and tilt data processing for monitoring groundwater contamination, Eos Trans. AGU, 84(46), Fall Meet. Suppl., Abstract H22C-0942, 2003.

Zhang, J., Wempe, W., Spetzler, H.A., 2002. Field measurements of the seismic absorption and Earth strain in partially fluid saturated porous media, Eos Trans. AGU, 83(47), Fall Meet. Suppl., Abstract H11E-0905. 